\title{
PbS sub-micron structures with anisotropic shape: Ribbons, Wires, Octa-pods and Hollowed Cubes
}

\author{
M. Bashouti and E. Lifshitz ${ }^{1}$ \\ Department of Chemistry and Solid state, Technion Institute, Israel institute of \\ Technology, Haifa, 32000
}

Preparing the uni-precursor, $\left[\mathrm{Pb}\left(\mathbf{S}_{2} \mathbf{C N E t}_{2}\right)_{2}\right]_{2}$, molecules: The uni-precursor molecules were prepared by mixing 3.321 gram of lead nitrate $\left[\mathrm{PbNO}_{3}\right]$ (dissolved in $50 \mathrm{~mL}$ of water) with 2.2531 gram of sodium diethyldithiocarbomate hydrate $\left[\mathrm{Et}_{2} \mathrm{NCS}_{2} \mathrm{Na}^{*} 3 \mathrm{H}_{2} \mathrm{O}\right]$ (dissolved in $50 \mathrm{~mL}$ of water). The chemical product was filtered, dried by a warm carbon disulfide at $40^{\circ} \mathrm{C}$, and was left in vacuum for 24 hours. NMR analysis of the uni-precursor, shown in the Figure below, confirmed a high purity product. NMR spectra were recorded on Avance 300 spectrometer. Chemical shifts for ${ }^{1} \mathrm{H}-\mathrm{NMR}$ are referenced to internal solvent resonances and are reported relative to tetramethylsilane. ${ }^{1} \mathrm{H}$ NMR (300 MHz, $\left.\mathrm{CDCl} 3\right): \delta 3.74$ (q, J = 7 $\left.\mathrm{Hz}, 4 \mathrm{H}, \mathrm{NCH}_{2}\right) ; 1.28\left(\mathrm{t}, \mathrm{J}=7 \mathrm{~Hz}, 6 \mathrm{H}, \mathrm{CH}_{3}\right.$ ). This NMR found to fit the literature $\mathrm{NMR}^{2}$.

X-ray analyses: The crystallographic properties of the various $\mathrm{PbS}$ sub-micron structures were characterized by the use of an X-ray diffraction. Representative examples are shown in Figure 1, suggesting crystallographic rock salt structure symmetry with a unit cell dimension of $6.12 \AA$ relevant to a rock salt structure, with space group of Fmām. This means that the produced shapes initiates from the same nuclei, however, they develop differently, according to the growth external conditions. The XRD of the cubes concides solely with the conventional X-ray data card 00-005-0592, while the XRD of the other shapes are similar to the cubic structure, but, show some deviation, that may be associated with the existence of excess sulphur or excess lead at different facets.

(1) To whom correspondence should be address, Department of Chemistry and Solid State Institute, Technion, Haifa 32000, Israel. E-mail: (E. Lifshtiz, ssefrat@tx.technion.ac.il).

(2) Tito, T; Paul, O; Xiao, M. Z; Majid, M, J. Mater. Chem 1997, 7, 1011-1016. 


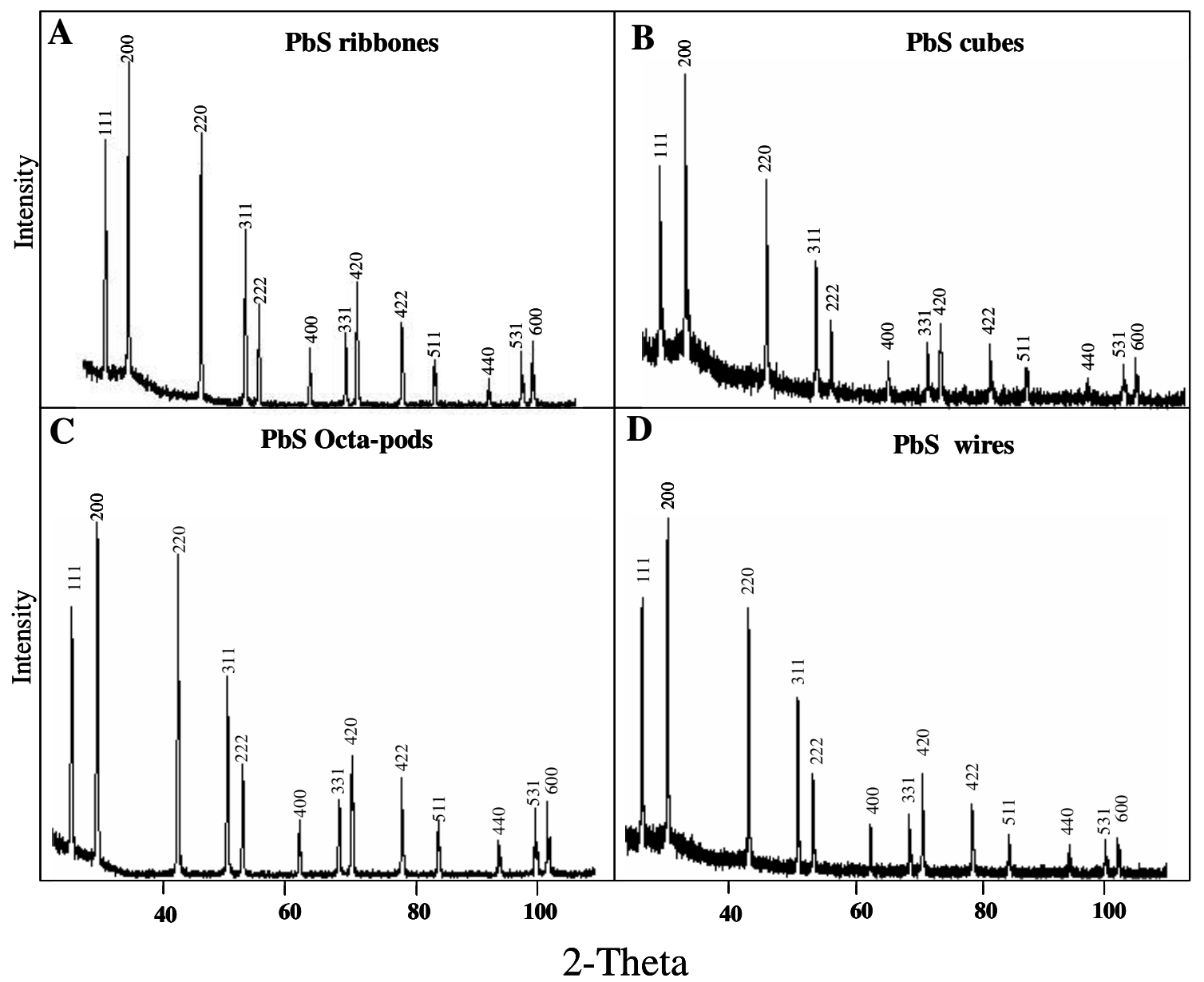

Figure 1: X-ray diffraction patterns of PbS ribbons (A), Cubes (B), Octa-pods (C) and wires (D).

\section{HR-SEM measurements of the PbS wires}

Figure 2 show representative HR-SEM images of $\mathrm{PbS}$ wires, obtained in ethylenediamine solution, at low temperatures $\left(80^{\circ} \mathrm{C}\right)$, after a duration of about 40 minutes. The XRD of those wires are shown in Figure 1D.

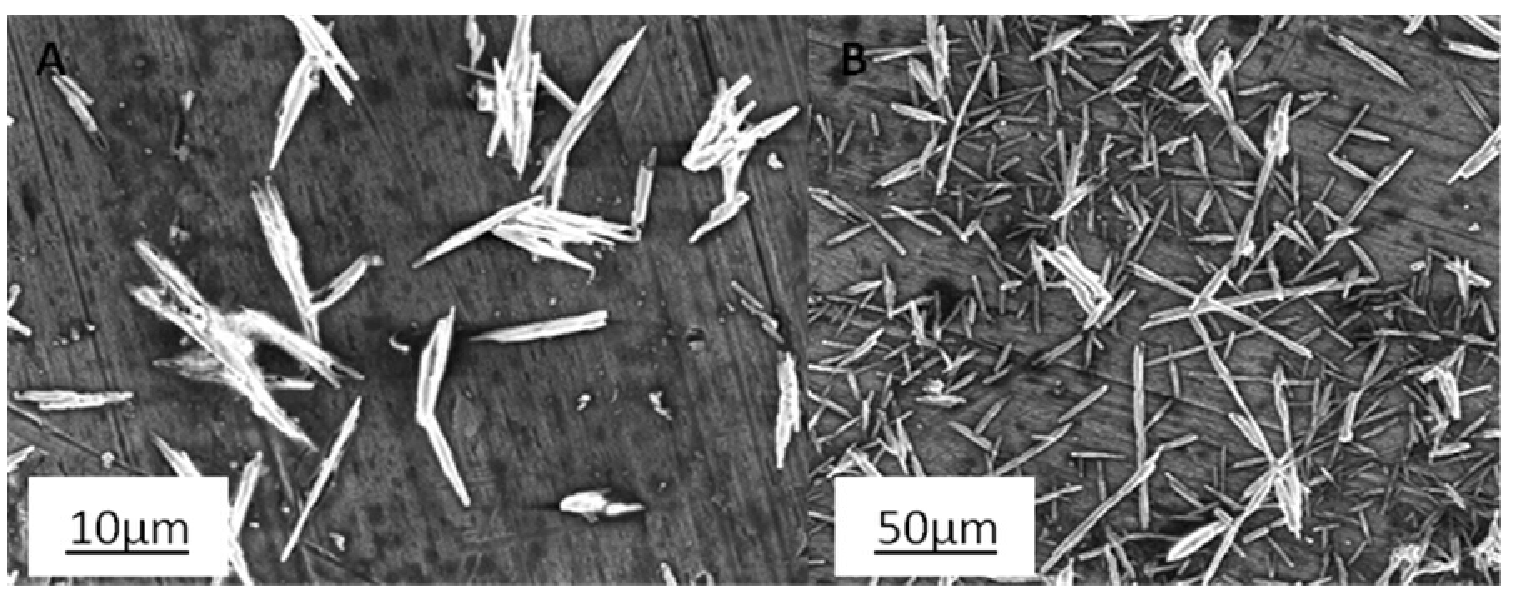


Figure 2: HR-SEM images of $\mathrm{PbS}$ wires

Energy dispersive analysis of X-ray (EDAX): Atomic percentages of the $\mathrm{Pb}$ and $\mathrm{Se}$ elements in the PbS crystals were derived from the EDAX, suggesting a consistence appearance of a $\mathrm{Pb}: \mathrm{S}$ molar ratio of 1:1 in the wires, ribbons, octa-pods and cube structures. Representative example of the EDAX is shown in Figure 3 and in Table 1 of this supporting information.

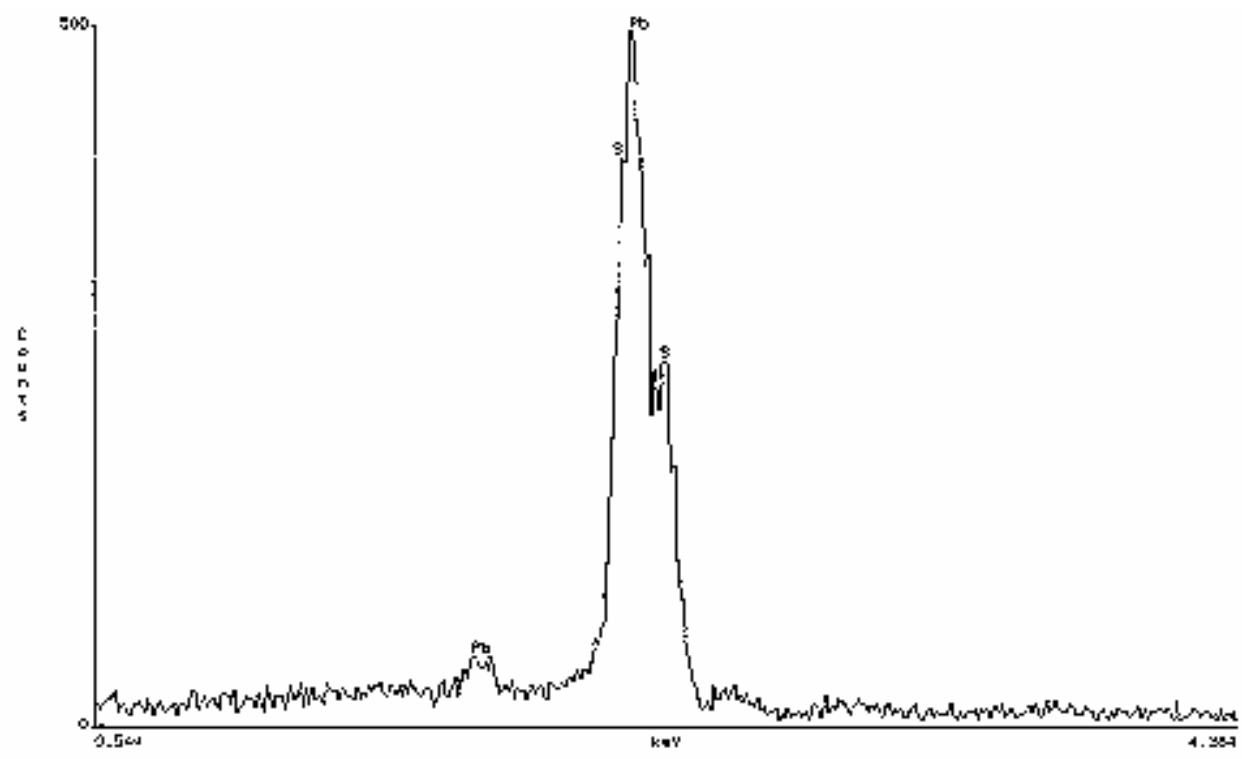

Figure 3: EDAX spectrum of $\mathrm{PbS}$ sub-micron structure

Table 1: Atomic percentages of $\mathrm{Pb}, \mathrm{S}$ constituents in $\mathrm{PbS}$ sub-micron crystals, as derived from the EDAX data.

\begin{tabular}{|c|c|c|}
\hline Element & Atom & Element weight \\
\hline $\mathrm{S}-\mathrm{K}$ & 50.90 & 15.32 \\
\hline $\mathrm{Pb}-\mathrm{M}$ & 49.10 & 84.68 \\
\hline
\end{tabular}

